\title{
A new approach to inelastic structural design
}

\author{
by \\ M. G. Lay
}

Messrs F. Sawko and A. M. B. Wilde (Dept of Civil Engineering, Leeds University) wrote that they had read with interest Dr Lay's Paper, and would like to comment on a number of points raised.

42. The title of the Paper was somewhat misleading in describing its contents. Dr Lay's Paper might be divided into two parts. In the first he examined critically the 'simple plastic hinge' pointing out the inconsistencies resulting from its application to the analysis of actual steel frames in the post-elastic state. He then proposed his 'circular length' concept as a more suitable alternative. In the second, he developed a method of elasto-plastic analysis based on the new concept. Structural design did not seem to have been discussed at all. In fact, direct design, in the plastic method sense of the word, where proportioning of section sizes was achieved once loading and frame geometry were specified was impossible with the new approach, which required the prior knowledge of section properties.

43. Dr Lay's article was a lucid description of the mechanism of formation and spread of plasticity along a member loaded in the post elastic region, and provided an excellent explanation as to why no failures of structures designed on the basis of simple plastic theory had occurred through material fracture (\$4).

44. The reason was to be found in strain hardening, which effectively caused the spreading of plastic zones along the length of member, thus preventing excessive material strains. It should be pointed out, however, that workers in plastic theory had recognized this spreading of zones of plasticity, but assumed that, for the purpose of analysis, the spreading could be neglected and rotations assumed to be concentrated at the ends of members as plastic hinges.

45. In an effort to achieve relative simplicity in the 'circular length' approach, the Author had simplified his equation (15). The contribution to the inelastic deflexion from the Author's equation was:

$$
p=(s-1)\left(\frac{P L}{M_{\mathrm{p}}}-1\right)\left(\frac{M_{\mathrm{p}} L^{2}}{E I}\right)
$$

whereas a more accurate expression should read

$$
p=\left(1-\frac{M_{\mathrm{p}}}{P L}\right) \frac{M_{\mathrm{p}} L^{2}}{E I}\left[\left(s \frac{M_{\mathrm{g}}}{M_{\mathrm{p}}}-1\right)+\frac{1}{2}\left(\frac{P L}{M_{\mathrm{p}}}-1\right)\left(h^{\prime}-1\right)\right]
$$

where $M_{y}$ was the yield moment.

46. The differences between the two equations were caused by

(a) assuming a unit shape factor,

(b) including the effect of additional elastic curvature obtained in increasing the moment from $M_{\mathrm{p}}$ to $M_{\mathrm{o}}$ which had already been included in the elastic component of the deflexion equation,

(c) omitting component III of Fig. 7 which, as the Author pointed out, was necessary to linearize the deflexion equation. 


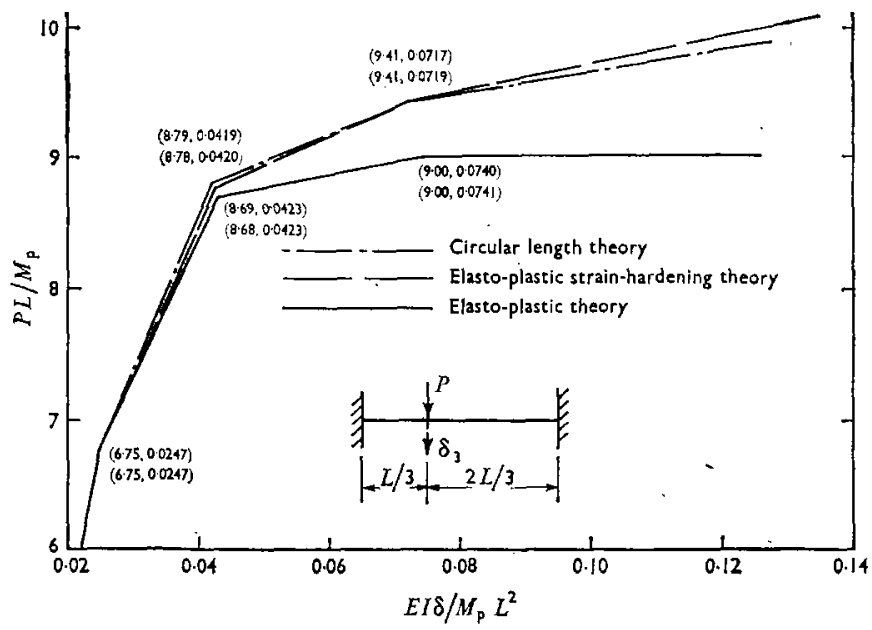

FIG. 14

47. The contributors had undertaken a series of tests at Leeds on commercial sections in steel to B.S. 968. The error brought about by using Dr Lay's equation was approximately $23 \%$, which the contributors felt was quite considerable.

48. In $\S 34, \mathrm{Dr}$ Lay mentioned and largely dismissed Sawko's ${ }^{19}$ proposal of a 'strain hardening' hinge. His comments on the effect of bending moment distribution on the $\beta$ factor were valid, but it was easy to take account of this automatically within a digital computer. ${ }^{29}$ The contributors felt that Dr. Lay should have compared his 'circular length' approach with the 'strain hardening' hinge, rather than the simple plastic hinge. It was in this light, that the contributors wished to discuss the remaining points.

49. It was immediately evident that the strain hardening hinge would produce the same diagram in Fig. 8 as the Author's approach. With a gradually increasing point load $\boldsymbol{P}$ at the end of a cantilever, deflexions would initially be elastic until the 'initial' plastic moment of the section $\left(M_{\mathrm{p}}\right)$ was developed, and would proceed to increase monotonically in a straight line, as in Dr Lay's case. Clearly if $\tau$ was small compared to unity, the error produced by the hinge assumption was negligible compared with the actual condition, and was certainly far less than the $23 \%$ involved in Dr Lay's idealization.

50. To demonstrate this fact, Dr Lay's example (Fig. 11) was re-analysed using the contributors" computer program ${ }^{29}$ based on the strain hardening hinge approach and the simple plastic theory, the results being compared in Fig. 14. The negligible discrepancies between the two might have been caused as much by the idealizations as by the numerical round-off errors either in the computer solution or in Dr Lay's calculations. In the light of these results, it was obvious that arguments concerning the relative accuracy of the two approaches were futile, and the relative merits of the two idealizations lay in their relative ease of application to the analysis of indeterminate structures.

51. Dr Lay's method was based on the extension of the basic flexibility approach for the analysis of statically indeterminate structures. Flexibility method was, and would always remain largely a hand method with a computer used to perform the 
arithmetic involved, once the initial release system was selected and diagrams corresponding to unit values of releases produced. It was this freedom of selection of the release system that made the method attractive for a number of problems, but statical indeterminancy $N$ had to be reasonably small. For $N=9$, equivalent to a single-bay three-storey frame, or three-bay single-storey portal, both with encased stanchions, the initial computations involved rendered the method uneconomic for everyday use. Dr Lay imposed a further restriction on the release system to be selected, rendering the method even less suitable for these structures. Because of this restriction, the 'best' release system from the point of view of conditioning of equation would probably not be obtained, and the example in Fig. 9 was a good indication of this. It would be interesting to see a suitable release system for a 'closed' type of structure, such as a two-bay two-storey frame-for which all plastic theories were intended. In spite of the matrix formulation, it must be emphasized that Dr Lay's approach would always remain a hand method, with the computer utilized only for performing arithmetical calculations.

52. The contributors' method of analysis of strain hardening structures was based on the stiffness approach with the 'strain-hardening' hinge concept. ${ }^{19}$ The electronic computer program ${ }^{29}$ required the specification of frame geometry and loading, and carried out the complete analysis both in the elastic and elasto-plastic strain hardening range automatically until the collapse load of the structure was achieved by instability, or when deflexions became excessive. Present work was also proceeding on the automatic analysis for change of geometry due to large deflexions. ${ }^{30}$ It was possible to incorporate all these effects in the stiffness approach without very much difficulty.

53. In conclusion, the contributors felt that Dr Lay had provided an excellent explanation of the role played by strain hardening in the plastic behaviour of structures, but that his proposed method of analysis based on the 'circular length' concept was of very limited practical use.

Dr J. M. Davies (Ove Arup and Partners, Edinburgh) appreciated the detailed consideration given by Dr Lay to the true behaviour of plastic hinges in steel structures and, in particular, his consideration of the effect of strain hardening.

55. If Dr Lay's treatment of the behaviour of a plastic hinge was compared with that of Horne, ${ }^{17.31}$ it became evident that, once Dr Lay had included sufficient approximations to make his treatment amenable to analysis, he was left with precisely the same relationship between bending moment $M_{\mathrm{o}}$ and plastic hinge rotation $\theta_{\mathrm{H}}$ as that deduced by Horne in his 'rigid-plastic-rigid theory'. Horne's relationship could be most conveniently expressed as

$$
M_{\mathrm{o}}-M_{\mathrm{p}}=\frac{E I}{k_{\mathrm{H}} h_{\mathrm{H}}} \theta_{\mathrm{H}}
$$

where $h_{\mathrm{H}}$ has dimensions of length and reflected the influence of the shape of the bending moment diagram in the vicinity of a plastic hinge on the behaviour of that hinge and $k_{\mathrm{H}}$ was a property of the steel related to Lay's factor $s$. It was Horne's original intention that $k_{\mathrm{H}}$ should be defined as $s-1$, but it had since become evident that better results were obtained with a rather higher value.

56. In the matrix analysis given in the latter part of the Paper, $\alpha_{k}$ was described as a coefficient found from an assumed B.M.D. and could be deduced from the table of symbols to be equal to $1 / h_{\mathrm{H}}$. It then followed that $\gamma_{\mathrm{r}}=k_{\mathrm{H}}\left(h_{\mathrm{H}} / L\right)$ and that equations (25) to (27) reduced to the equation given above. Thus, in practice, the "circular length analogy' became a 'rigid-plastic-rigid' approach.

57. It might therefore be of interest to note that the writer's equation had been incorporated in an elastic-plastic structural analysis and used by him to follow the elastic-plastic response of a number of experimental beams and frames to both static 
and variable repeated loading. ${ }^{32}$ The latter in particular offered a very sensitive test for the strain hardening properties of a plastic hinge and the degree of agreement between experiment and theory was in all cases most encouraging.

Messrs R. H. Wood and E. H. Roberts (Building Research Station) wrote that Dr Lay has dealt with the difficult subject of strain hardening of plastic hinges in beam-column structures. His suggestion that the assumption of ductile deformations with constant curvature over a short length of beam should be used instead of the localized and idealized 'hinge' in present day literature, was a convenient device, and it could be shown that this approximation gave results very close to the exact solutions investigated by the writers at the Building Research Station. In particular Dr Lay threw further light on Professor Horne's previous suggestion of using a 'rigid-plasticrigid' approach for the simplification of strain-hardening hinges (Fig. 12). This implied that, after some yielding at constant moment, a hinge might lock itself and become rigid again, and the idea had long seemed to be a questionable basis for the avoidance of frame instability in the inelastic range.

59. For some time the writers had been investigating the behaviour of structures when the stress/strain relationships or moment/curvature relationships might have

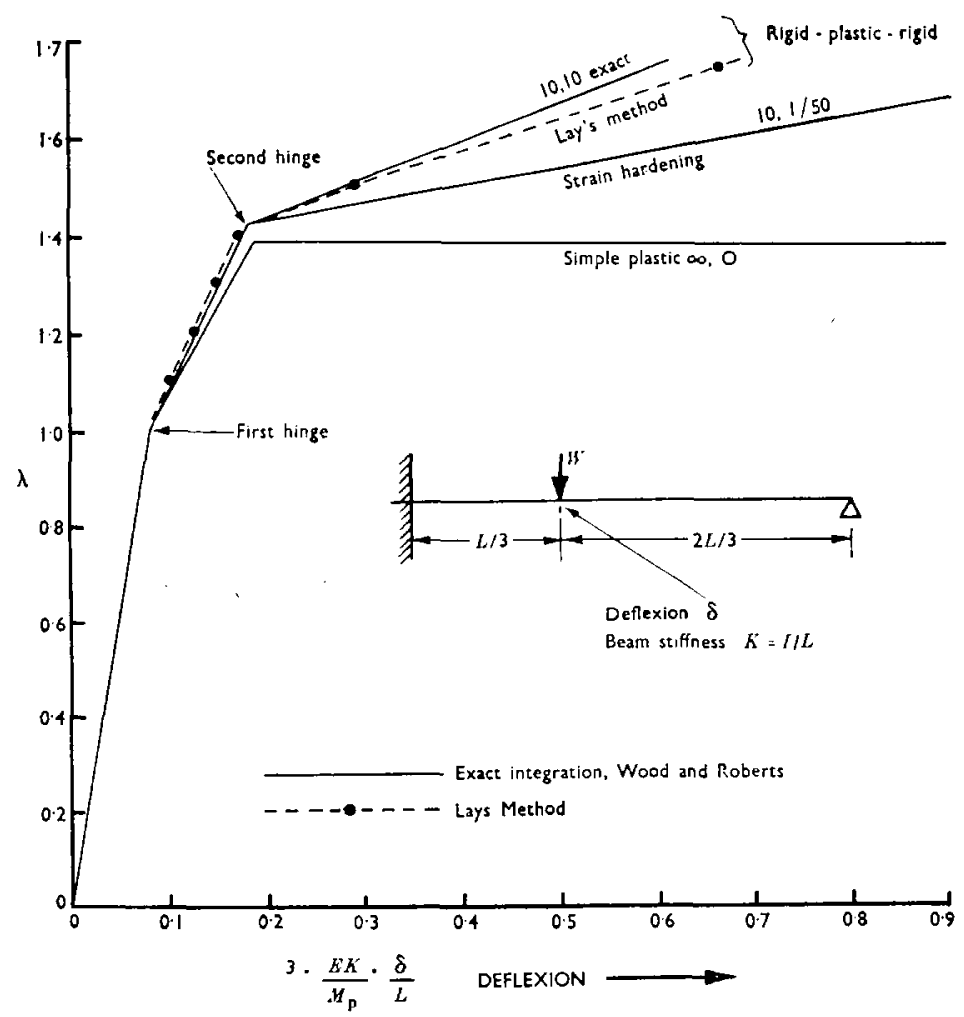

Fig. 15: Behaviour of Beam With Strain hardening Plastic hinges (Properties SHOWN IN FIG. 2) 


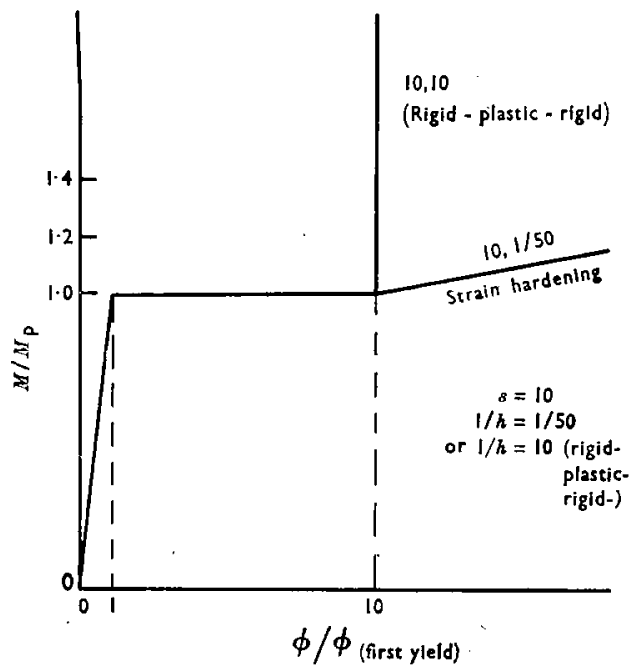

Fig. 16: Moment/Curvature Characteristics for Plastic hinges of BEAM IN Fig. 1

any possible shape, for example those shown in Figs 15 and 16 . One such set of results for portal frames had been given previously, ${ }^{33}$ where a complete graphical plot of moment-rotation characteristics for beams was obtained by numerical integration, and where it appeared that limiting deflexions controlled the design, rather than collapse loads. This exact procedure was used employing a computer to check Dr Lay's proposed 'circular length' approximation for the special case of the clamped and propped beam of Fig. 15, where it was seen that Lay's simplified method gave excellent results for the rigid-plastic-rigid case. This therefore corroborated the concept of 'circular length' as a first approximation. The method would no doubt be easy to apply with computers, but was probably too involved for designer's desk calculations.

60. It seemed to the writers that the description 'circular length' was unfortunate. At first glance this might give the impression that there was some kind of graphical construction required to find the length of the hinge, whereas the length used came directly from the bending diagram. They suggested that 'constant-curvature length' was more descriptive, since this was the physical meaning of the term, the assumption being that, even if the bending moment was altering along this short length, the curvature was assumed constant if the member was yielding. The title ' $A$ new approach to inelastic structural design' was also too generalized, because the method broke down for 'strain-softening' hinges. Moreover it was only applicable to beamcolumn structures.

61. The Author was critical of the concept of deteriorated critical loads of structures. It had however to be remembered that, at the time of presentation (about 1958 onwards) of various papers on frame instability, all plastic design had hitherto proceeded on a basis of constant-moment hinges. Very little was known, or even suspected at that time, concerning the possible disastrous effects which could be produced in tall buildings if a multitude of plastic constant-moment hinges developed. Three features had to be borne in mind.

62. The first of these was the strengthening effect of strain hardening. In demonstrating frame instability, it was recognized that strain hardening would help to reduce instability effects. However, as shown in Fig. 15, the rigid-plastic-rigid approach 


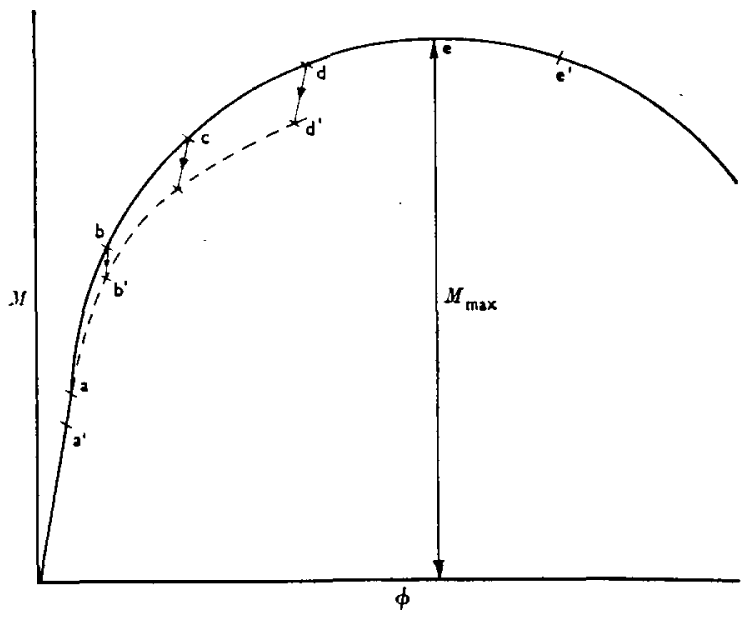

Fig. 17: Moment/Curvature Properties of beAm OF Fig. 18

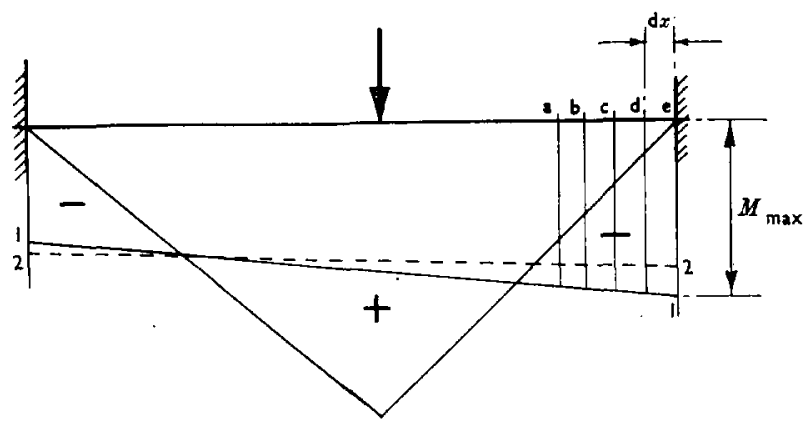

Fig. 18: Bending moment diagrams for a DAMPed beAm With STRAiN-SOFtening HINGES

over-estimated the strengthening effect of strain hardening. Strain hardening would be the least effective where there were a large number of plastic hinges in tall frames, and, as a consequence, an exceptional deterioration of stiffness.

63. The second point was the effect of frame instability on the calculations, during the design stage. If the actual moment/curvature relationship was replaced by a flat-topped diagram in the calculations, and even if safe curvature limits ${ }^{34}$ (such as the limits $L_{1}$ and $L_{2}$ proposed by Professor A. L. L. Baker) were provided, then this simplification would have the result that the full effects of deteriorated critical loads would be encountered in the computations. Such 'safe' limits would not therefore avoid the problem of frame instability during the calculations themselves, even if the 
frame itself would give a better performance. This point should not be forgotten. It was known that, for strain hardening hinges, a more complete set of calculations was essential to explain the behaviour.

64. The third feature was the problem of stability associated with 'strain softening' hinges. The writers had recently discovered that 'strain softening' hinges, i.e. those hinges which displayed a maximum moment followed by a falling-moment characteristic (Fig. 17) gave rise to severe analytical problems, amounting in this case to a complete breakdown of the theory of simple bending used by engineers. Thus the stability of reinforced concrete frames needed careful study, since reinforced concrete members frequently had this characteristic, and indeed the $L_{1}, L_{2}$ limits had often been used in this setting. With a clamped beam loaded as in Fig. 18, at some stage in the loading the restraint moment line became $1-1$, corresponding to the attainment of maximum moment at the right hand support. Thus positions $a, b, c, d, e$, on the beam had corresponding points a ... e on the $M / \phi$ diagram of Fig. 17, where $\mathrm{e}$ had reached the top of the curve. Any further increase in load caused $\mathrm{e}$ to move to the point $\mathrm{e}^{\prime}$ beyond the top of the curve, with further yielding, and the restraint moment line became, for example, line 22. However, since equilibrium must always be satisfied, the moments at $a, b, c, d$ must then be reduced. This however resulted in the opposite effect, namely strain recovery, the corresponding points being $a^{\prime}, b^{\prime}, c^{\prime}, d^{\prime}$. Now if point $d$ on the beam was considered to be at a small distance $\mathrm{d} x$ from the support $\mathrm{e}$, there was a pronounced discontinuity with strains increasing at one section and decreasing at a nearby section. Indeed as $\mathrm{d} x \rightarrow 0$ all points on the beam, other than at the actual support itself, showed decreasing strain. There was no rotation of the discontinuity zone, i.e. $\phi . d x \rightarrow 0$, since the curvature $\phi$ was finite. The beam remained perfectly encastered thereabouts with no end rotation and moreover straightened out slightly. (Shortly afterwards a similar performance would be repeated at the beam centre at a slightly higher load.)

65. Clearly an impasse had been reached, at least mathematically, for, although there was a downward branch of the $M / \phi$ curve, apparently no part of the beam proper ever made use of it. The calculations came to a halt. To explain this breakdown it was necessary to return to the starting assumptions. The idealizations behind the theory of simple bending were thus suspect, and in particular the statement that plane sections remained plane. This feature was at present under examination by the writers at the Building Research Station using a computer. It was necessary to treat plastic 'hinges' as a more detailed and complex problem in elasto-plastic plane stress. Eventually this subject linked up with the behaviour of membranes and walls in the inelastic phase, whilst Barnard ${ }^{35}$ had linked it with the dynamic collapse of beams. As far as 'hinges' were concerned it was necessary to find some approximate indication of the 'extent' of the hinge, by recourse to more advanced analysis. The bending moment diagram itself could not be used with strain-softening hinges to find the circular length $\tau \times L$. For this reason and others the generality of the Author's new approach should be treated with reserve.

The Author thanked the contributors for their discussions and for the interesting points raised. In particular, the contribution of Wood and Roberts was constructive and worth careful reading. It was also of interest to read the three contributions in conjunction. Points raised by one contributor were found to be answered by another and, in other cases, not only was there disagreement between the Author and the individual contributor but differences of opinion among the contributors themselves. This situation was not surprising since the real importance of strain hardening in predictions of structural behaviour had only recently been realized and no comprehensive experimental background to the problem currently existed.

67. Sawko and Wilde had queried the title chosen for the Paper. Their criticism might have been valid had the title been 'A New Method for Inelastic Structural Design', but it was, in fact, 'A New Approach to Inelastic Structural Design' and 
it seemed to Dr Lay that any literal interpretation of this title would imply an attempt to lead designers to a consideration of structural design from a new aspect. Furthermore, although the Author was well aware of the current academic connotations associated with the word 'design', he still preferred to use the word in its broader professional sense. A more searching criticism of the title was supplied by Wood and Roberts. The Paper was intended to be applied only to the pre-local buckling behaviour of structural steel. In this circumstance strain softening would be precluded. It was interesting to note that post-local buckling behaviour would also produce an apparent strain softening and as there was no reason why local buckling, per se, should be avoided in structural situations, Dr Lay awaited Wood's and Robert's work in this field with great interest.

68. He very strongly believed that $\S 47$ was both unfortunate in its presentation and disturbing in its technical implications. If the tests which Messrs Sawko and Wilde had used suggested $23 \%$ discrepancies then it would seem that they had a most powerful obligation to quote some details of the tests. As it was, Dr Lay was defenceless against this unsupported and unreferenced assertion. He would like to know what the $23 \%$ was relative to and what was being discussed, loads, deflexions or strains. At what level of load or deflexion was the $23 \%$ measured? Was it a failure load, and if so how was failure defined? What sort of test was it--beam, column or frame? What was the section used? What were the material properties? How were the strain-hardening exponents of the material measured? Dr Lay deplored the lack of support to such statements in a technical discussion. The only information given was that the tests were on commercial sections to B.S. 968 (1941 or 1962 ?).

69. The Author's own experience in testing higher strength steels $8,7,9,10,13,14,27$ had indicated the critical nature of measurements of the strain-hardening exponents. Work by Adams ${ }^{36,37}$ and Yura ${ }^{38}$ seemed to confirm this and had also indicated the influence of several previously unsuspected variables. One of these was the manner in which the section under consideration was cold-straightened in the mill. ${ }^{37}$

70. Dr Lay had chosen to compare his circular length method with the plastic hinge method rather than with the 'strain hardening hinge', as suggested by Sawko and Wilde, for the simple reason that no valid formulation of this last concept was available when the Paper was written. In point of fact, neither reference 29 nor 30 was published at the time and neither had been made available to the Author. It might be suggested to the contributors that the term 'strain hardening hinge' is a rather self-contradictory one.

71. To a large extent, Sawko and Wilde's criticism of the efficacy of the design method ( $\$ 51$ ) depended on the goals set for a design method to achieve. To this extent, the academic, with his search for generality and universality would formulate a different set of goals from the designer who required a method suitable for handling the majority of cases commonly encountered in practice, without the solution being removed too far from the reach of his intuitive understanding. The Author's aims in formulating his method were: (a) to create a method which represented the behaviour of inelastic structures more consistently and accurately than existing methods, (b) to construct the method in such a way that the computer could be used to remove most of the arithmetical drudgery, and (c) to allow the designer to retain an appreciation (a 'feel') for the import and implications of his calculations and manipulations. The Author believed that he had achieved these goals. He had not had access to References 29 and 30 and so could not comment on the contributors' method.

72. However, as a general comment, the Author believed that the time had come for designers to make a critical appraisal of many computer methods. Too often the data and output were both formulated in such a manner that they were not liable to the same professional examination which they would receive if part of a manual design. For example, the computer had no current facility for telling a designer that 
his design contained sections at variance with those which he had earlier selected for similar designs.

73. Finally, Dr Lay suggested that his method had certain advantages as a vehicle for explaining inelastic structural behaviour. It remained closely related to firmly established elastic design techniques and the various important structural occurrences could be observed as the calculations developed. In particular, the onset of local buckling could be readily predicted and the controlling influence of this phenomenon was becoming increasingly apparent. ${ }^{38}$

74. It was gratifying to read in all the contributions of the close agreement between the predictions reached by the Author's method and those of the contributors.

75. Dr Davies' contribution was of interest. The Author had recognized the close similarity between some of his assumptions and those of Professor Horne ( $\$ 32)$. The two approaches to hinge curvature were not quite identical as the Author's included, as an addition, the contribution of elastic curvatures related to $M_{0}$. Of course, this explained why Horne had obtained better agreement with the use of $s$ instead of $s-1$ (in the Author's method the addition of elastic effects is approximately equivalent to Horne's addition of 1 to $s-1$ ). It was a pity that $\mathrm{Dr}$ Davies did not make reference to his own excellent recent paper $^{39}$ which threw further light on the strain-hardening problem.

76. The general interest of the contribution of Wood and Roberts had already been noted. In reply to the comment in the last line of $\S 59$, Dr Lay had analysed a number of his own structures manually, using the method described in the Paper and found the process to be no more tedious than the manual solution of a similar elastic structure. This was a very subjective matter but it certainly did not seem that the method was any less amenable to hand calculation than was the calculation of deflexions in a redundant elastic structure.

77. He had no objection to the term 'constant curvature' proposed by these contributors as a replacement for the term 'circular length'. It was also noted that Baker's 'safe curvature limits' for concrete ${ }^{34}$ had a strong resemblance to the Author's local buckling limits for steel ${ }^{13.14}$ (these limited the size of $\tau L$ ). Dr Lay had noted that English workers generally tended to discount the influence of local buckling and it might well be useful to draw attention to Yura's recent frame tests. ${ }^{38}$ A final plea might be made for the accurate measurement of the strain hardening properties of steels used in current and future test programmes. Dr Davies' recent paper ${ }^{39}$ had illustrated how necessary this information was if the results of past experimental tests were to be rationally assessed.

\section{REFERENCES}

29. SAWko F. and WiLde A. M. B. The automatic analysis of strain hardening structures (in preparation).

30. WILDE A. M. B. Strain hardening effects in steel structures. Dissertation for Ph.D. thesis, University of Leeds (in preparation).

31. HoRne M. R. and MedLand I. C. Collapse loads of steel frameworks allowing for the effect of strain hardening. Proc. Instn civ. Engrs, 1966, 33 (March) $381-402$.

32. Davies J. M. The stability of plane frameworks under static and repeated loading. Ph.D. Thesis, University of Manchester, 1965.

33. WOOD R. H. Discussion on Use of the plastic theory in the design of a fabricating shop (Baker, Horne and Johnson). Proc. Instn civ. Engrs, 1963, 24 (March) 390-393.

34. Ultimate load design of concrete structures. Report of Research Committee of the Institution of Civil Engineers. Proc. Instn civ. Engrs, 1962, 21 (Feb.) $400-442$.

35. Barnard P. R. The collapse of reinforced concrete beams. Proc. Symp, on Mechanics of Reinforced Concrete. ASCE-ACI Publication, 1965. 
36. ADAMS P. Determination of the static yield level and the strain-hardening modulus. Fritz Engrg Lab. Rep. No. 297.7, March 1964.

37. AdAMS P. Plastic design in high strength steel. Fritz Engrg Lab. Rep. No. 297.19, May 1966.

38. YURA J. The strength of braced multi-storey frames. Fritz Engrg Lab. Rep. No. 273.28, Sept. 1965.

39. Davies M. Frame instability and strain hardening in plastic theory. Proc. Am. Soc. civ. Engrs, 1966, 92 (ST3) (June) 1-15. 